\title{
An Analytical Approach for Levee Underseepage Analysis
}

\author{
Christopher L. Meehan ${ }^{1}$; Sittinan Benjasupattananan ${ }^{2}$
}

\begin{abstract}
Levee underseepage analyses are commonly performed to assess the risk of erosion and piping of levee foundation soils. They are also commonly used to estimate the quantity of seepage that is expected to pass beneath a levee over time, and to assess the risk of excessively high pore pressures at various points in the foundation. A variety of approaches have historically been utilized to perform steady-state underseepage analyses in levees, including flow-nets, closed-form analytical solutions, and numerical techniques such as finite difference or finite element analyses. This paper provides a derivation of a series of closed-form "blanket theory" analytical equations that can be used to perform a levee underseepage analysis. This derivation starts from a generic confined flow analytical solution, of the type that is common in groundwater flow analyses. The solution is then extended to simulate semiconfined flow beneath a levee in a shallow aquifer. Equations are presented for calculating total head and seepage quantity values for different model boundary conditions. A typical example problem is used to compare the analytical equations that are derived with the analytical equations that are presented in the US Army Corps of Engineers (USACE) levee design manual. The results provide validation for both the equations that are presented and the conventional USACE analytical design approach. Using the results from the example problem, general guidance and suggestions are provided for designers that use closed-form analytical approaches for modeling levee underseepage.
\end{abstract}

DOI: $10.1016 /$ j.jhydrol.2012.08.050

Keywords: Analytical approach; Groundwater flow; Levees; Underseepage; Pressure head; Seepage quantity.

Copyright: This paper is part of the Journal of Hydrology, Vol. 470-471, November 2012, ISSN 0022-1694. The copyright for this work is held by Elsevier B. V. The original publication of this work can be obtained by following the DOI link above.

Reference: Meehan, C.L. and Benjasupattananan, S. (2012). "An Analytical Approach for Levee Underseepage Analysis." Journal of Hydrology, Elsevier, 470-471, 201-211. (doi:10.1016/j.jhydrol.2012.08.050)

Note: The manuscript for this paper was submitted for review and possible publication on April 27, 2012; approved for publication on August 27, 2012; and published online in November of 2012.

\section{Introduction}

Levees are constructed embankments whose primary purpose is to provide flood protection from seasonal high water levels, typically along rivers (USACE, 2000). If a levee is designed to be relatively impermeable, any seepage of water that occurs from the riverside to the landside of the levee will be concentrated in its foundation, rather than through the body of the levee itself. For purposes of design, steady-state seepage conditions are typically assumed to occur beneath a relatively impermeable levee during a flood event, with the maximum flood-stage water elevation on the riverside of the levee, and the water elevation at the base of the levee on its landside (USACE, 2000).

In order to assess the risk of excessively high pore pressures in the levee foundation that could lead to erosion of

\footnotetext{
${ }^{1}$ Bentley Systems Incorporated Chair of Civil Engineering \& Associate Professor, University of Delaware, Dept. of Civil and Environmental Engineering, 301 DuPont Hall, Newark, DE 19716, U.S.A. E-mail: cmeehan@udel.edu (corresponding author)

${ }^{2}$ Graduate Student, University of Delaware, Dept. of Civil and Environmental Engineering, 301 DuPont Hall, Newark, DE 19716, U.S.A. E-mail: sittinan@udel.edu
}

the foundation soil and formation of seepage pipes, it is necessary to perform a levee underseepage analysis. This type of analysis also provides additional critical information, such as an estimate of the quantity of seepage that passes through the levee foundation over time. A variety of approaches have historically been utilized to perform steady-state underseepage analyses in levees, including flow-nets (e.g., Freeze and Cherry, 1979; Cedergren, 1989), closed-form analytical solutions (e.g., Harr, 1962; Peter, 1982), and finite difference or finite element analysis of levee underseepage (e.g., Wolff, 1989; Gabr et al., 1995).

Currently, a commonly used approach for performing levee underseepage analysis in the United States is the simplified analytical method that was developed by the US Army Corps of Engineers (USACE, 2000). Although the equations that are presented in this engineering manual have been presented in a number of other publications (e.g., Bennett, 1946; USACE, 1956a; Turnbull and Mansur, 1959; Turnbull and Mansur, 1961), a complete list of the assumptions that have been made in their derivation, the derivations themselves, and clear guidance for 
their utilization are not readily available in the technical literature.

The goal of this paper is to provide a synopsis of a derivation of a series of closed-form "blanket theory" analytical equations that can be used to perform levee underseepage analyses (the complete derivation of these equations is available in Benjasupattananan, 2012). This derivation will start from a generic confined flow analytical solution, of the type that is common in groundwater flow analyses. The solution will then be extended to simulate semiconfined flow beneath a levee in a shallow aquifer. A number of equations will then be presented that provide a method for calculating total head and seepage quantity values for different model boundary conditions. A typical example problem is used to compare the analytical equations that are derived with the analytical equations that are presented in the USACE levee design manual (USACE, 2000). The results provide validation for both the equations that are presented and the conventional USACE analytical design approach. Using the results from the example problem, general guidance and suggestions are provided for designers that use closed-form analytical approaches for modeling levee underseepage.

\section{An Analytical Solution for Analyzing Confined Groundwater Flow}

Early studies by Henry Darcy (Darcy, 1856) laid the foundations for our understanding of the behavior of fluid as it flows through a porous media. Darcy's law (Darcy, 1856) is a constitutive equation that states that the amount of groundwater discharging through a given portion of an aquifer is proportional to the cross-sectional area of flow, the hydraulic head gradient, and the hydraulic conductivity. In the field of hydrogeology, Darcy's law is used along with the equation of conservation of mass to derive the groundwater flow equation. For steady-state groundwater flow conditions, the flow of groundwater can be described by Laplace's equation, a second-order partial differential equation which describes how flow is induced by potentials (e.g., USACE, 1993). (Laplace's equation has useful analogs in a number of fields, including electromagnetism, astronomy, and fluid dynamics, as it has been shown to govern the behavior of electric, gravitational, and fluid potentials).

Through its application as part of the groundwater flow equation, Darcy's law forms the basis for numerous "classical" analytical solutions in groundwater flow modeling, such as: the Theis equation (Theis, 1935), which is typically used to analyze the results of an aquifer test or slug test, the Thiem equation (Thiem, 1906), which is used to describe steady-state radial flow to a well that is being pumped, and the Hooghoudt equation (Hooghoudt, 1940), which is used to establish drain spacing requirements for the design of pipe drains, tile drains, or ditches. Through the groundwater flow equation, Darcy's law is used in a variety of forms and for a variety of problems in the field of hydrogeology. It is particularly well-suited to modeling the flow of groundwater in confined aquifers; this assertion is not surprising, since data collected for aquifer flow problems is what formed the basis for the original development of Darcy's law.

Incorporating developments in conceptual understanding from the field of hydrogeology that took place for over a century, Verruijt (1970) describes a mathematical approach that can be used for modeling the behavior of shallow semiconfined groundwater flow in an aquifer. As used here, the term confined flow applies to the field case where leakage through subsurface soil confining beds is negligibly small (Fig. 1). If the leakage through the confining beds is significant enough that it cannot be neglected, the aquifer is considered to be semiconfined. The term shallow semiconfined flow is used whenever an aquifer is sufficiently shallow such that the resistance to flow in the vertical direction may be neglected (Strack, 1989).

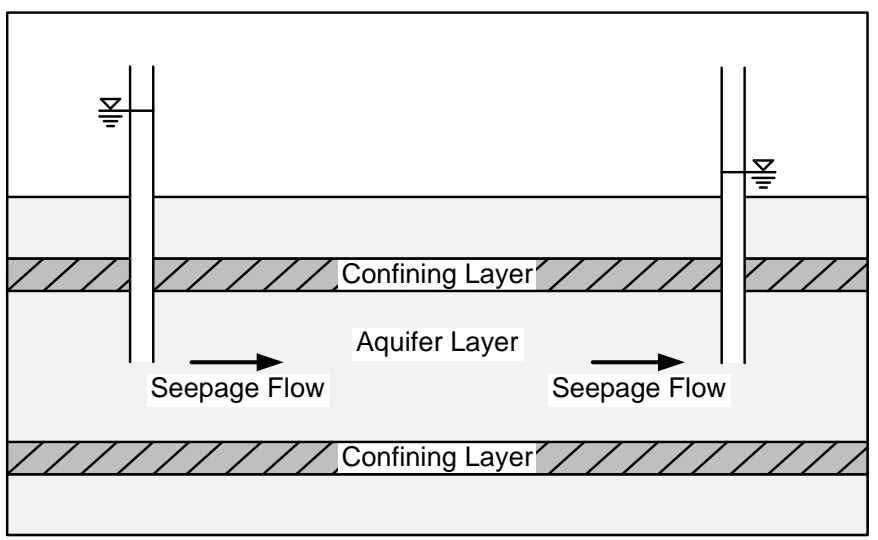

Fig. 1: Subsurface seepage between soil confining layers.

Following Verruijt's (1970) approach, the basic equation that governs steady-state confined groundwater flow in an isotropic homogeneous aquifer (Laplace's eq.) is introduced:

$$
\frac{\partial^{2} h}{\partial x^{2}}+\frac{\partial^{2} h}{\partial y^{2}}+\frac{\partial^{2} h}{\partial z^{2}}=0
$$

where $h$ is the total head, and $x, y$, and $z$ are the Cartesian coordinate directions ( $x$ and $y$ are typically used for the two coordinate directions that correspond to the plane of the aquifer, and $z$ is commonly used to refer to elevation, e.g., Fig. 2).

As shown in Fig. 1, if a soil is completely confined between two impermeable layers, the flow in the aquifer is one-dimensional. However, for a semiconfined aquifer, the flow regime is more complex. In particular, although the confining layers do have a low permeability, some amount of water may leave (or enter) the aquifer; this means it is not appropriate to disregard the vertical seepage flow that occurs through the confining layers altogether. At the same time, it is reasonable to expect that horizontal seepage flow in the confined permeable layer will dominate the resulting behavior. Consequently, in order to develop an equation for semiconfined flow that is derived directly from the fundamental principle of continuity and Darcy's 


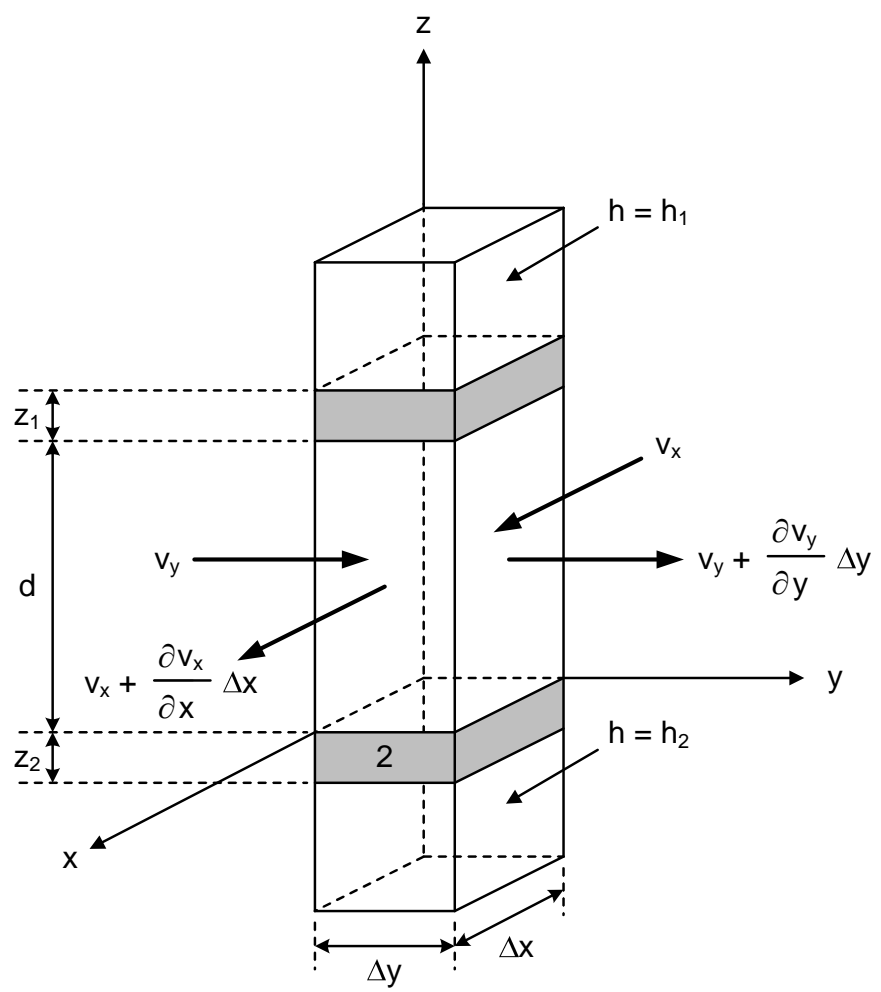

Fig. 2: Continuity of seepage in an element of a confined aquifer (modified after Verruijt (1970)).

law, Verruijt (1970) made the following assumptions: (1) That the permeable layer is of constant thickness, $d$, and (2) that vertical velocities in the permeable confined layer are small compared to the horizontal velocities.

The second assumption above is important in the derivation, as it indicates that in the permeable layer $\partial h / \partial z$ will be small compared to $\partial h / \partial x$ and $\partial h / \partial y$. Consequently, the head over the height of the permeable layer can be considered to be practically constant, which allows Laplace's equation to be reduced to:

$$
\frac{\partial^{2} h}{\partial x^{2}}+\frac{\partial^{2} h}{\partial y^{2}}=0
$$

To satisfy the criteria of one-dimensional flow that is critical for the derivation of Eq. (2), i.e., the assumption that the vertical flow components (in the $z$-direction) can be neglected, Bennett (1946) and Strack (1989) suggested that the coefficient of permeability for the confining layer(s) should be at least ten times smaller than that of the permeable aquifer layer.

Figure 2 shows an element in a semiconfined aquifer that has dimensions of $\Delta x$ by $\Delta y$ by $d$. Assuming continuity of seepage flow through this element, the following terms and equations can be derived to model the flow of seepage:

$$
Q_{x y}=\left(\frac{\partial v_{x}}{\partial x}+\frac{\partial v_{y}}{\partial y}\right) \Delta x \Delta y d
$$

where $v_{x}$ and $v_{y}$ are the components of the discharge velocity in the $x$ - and $y$-directions, respectively.
The net outward flux can be rewritten using Darcy's law as:

$$
Q_{x y}=-k\left(\frac{\partial^{2} h}{\partial x^{2}}+\frac{\partial^{2} h}{\partial y^{2}}\right) \Delta x \Delta y d
$$

where $k$ is the coefficient of permeability for flow through the aquifer and $h$ is the total head within the confined soil layer.

The amount of water percolating out of the element through the upper confining layer (layer 1) per unit time is given by the term:

$$
Q_{z 1}=k_{1}\left(\frac{h-h_{1}}{z_{1}}\right) \Delta x \Delta y
$$

where $h_{1}$ is the total head in the layer above confining layer 1 , and $k_{1}$ and $z_{1}$ are the coefficient of permeability and thickness of the semipermeable layer, respectively.

The amount of water percolating out of the element through the lower confining layer (layer 2) per unit time is given by the term:

$$
Q_{z 2}=k_{2}\left(\frac{h-h_{2}}{z_{2}}\right) \Delta x \Delta y
$$

where $h_{2}$ is the total head in the layer below confining layer 2 , and $k_{2}$ and $z_{2}$ are the coefficient of permeability and thickness of the semipermeable layer, respectively.

In order to satisfy continuity of flow through the element, the sum of the flow quantities in terms (4) - (6) must be zero, which leads to the following equation:

$$
k d\left(\frac{\partial^{2} h}{\partial x^{2}}+\frac{\partial^{2} h}{\partial y^{2}}\right)-\left(\frac{h-h_{1}}{m_{1}}\right)-\left(\frac{h-h_{2}}{m_{2}}\right)=0
$$

where $m_{1}=z_{1} / k_{1}$ and $m_{2}=z_{2} / k_{2}$. The values of "m" are commonly referred to as the hydraulic resistances of the semipermeable confining layers (Verruijt, 1970). Eq. (7) is the basic differential equation that describes steady flow in a semiconfined aquifer. It is also sometimes expressed in the following form:

$$
\frac{\partial^{2} h}{\partial x^{2}}+\frac{\partial^{2} h}{\partial y^{2}}=N
$$

where the term $N$, the leakage, is equal to:

$$
N=\left(\frac{h-h_{1}}{k m_{1} d}\right)+\left(\frac{h-h_{2}}{k m_{2} d}\right)=\left(\frac{h-h_{1}}{\lambda_{1}^{2}}\right)+\left(\frac{h-h_{2}}{\lambda_{2}^{2}}\right)
$$

The leakage factor, $\lambda$, introduced in Eq. (9) has the dimensions of length and is defined as:

$$
\lambda_{i}=\sqrt{\frac{k z_{i} d}{k_{i}}}
$$

where $i$ has a value of either 1 or 2 , depending upon which confining layer is being referred to. 


\section{The US Army Corps of Engineers Levee Underseepage Analysis Approach}

The concepts and approaches for analyzing groundwater flow that have been developed by Darcy (1856), which have seen extensive use in the field of hydrogeology (e.g., Thiem, 1906; Theis, 1935; Hooghoudt, 1940), have also been used for a wide variety of geotechnical engineering applications, such as modeling the seepage that occurs both through and beneath earth dams and levees. In particular, in situations where flow beneath an earthen dam or levee is confined by a lower permeability blanket layer (e.g., Fig. 3), the general concepts of confined groundwater flow that are discussed in the previous section are applicable, and similar analytical modeling approaches can be utilized. In typical dam and levee parlance, the more permeable aquifer through which water flows is referred to as the foundation, and the less permeable confining layer where water is infiltrating or exfiltrating is commonly referred to as the semipervious blanket (Fig. 3).

Utilizing the concepts and approaches for analyzing confined groundwater flow that are described in the previous section, Uginchus (1935) presented a mathematical approach for modeling the seepage flow that occurs through semipermeable dam aprons. In a similar fashion, Bennett (1946) presented a detailed analytical approach for accounting for the effect of semipervious blankets on seepage through pervious dam or levee foundations; this particular body of work had a relatively significant impact on levee underseepage analysis techniques that are used in US practice. Associated discussions to the Bennett paper presented by R.A. Barron, V.A. Endersby, H.R. Cedergren, W.J. Turnbull, and K.S. Lane suggested valuable modifications and additional applications of Bennett's general approach, which taken together, provide guidance and a useful analytical framework for modeling levee underseepage. This general analytical framework was later adopted by the United States Army Corps of Engineers (USACE) in a detailed field study of levee underseepage in the Mississippi River levee system (USACE, 1956a, 1956b; Turnbull and Mansur, 1961). These studies eventually led the USACE to formally adopt this analytical methodology as their primary approach for analyzing levee underseepage, as described in the current USACE levee design manual (USACE, 2000).

The USACE (2000) levee underseepage analysis approach assumes that a given levee foundation can be generalized as having a pervious sand or gravel stratum with a uniform thickness and permeability that is overlain by a semipervious or impervious top stratum with a uniform thickness and permeability (Fig. 3). For more complex geologies, USACE (2000) provides equations for generalizing ("transforming") multi-layer systems into an equivalent two-layer system that can be used in conjunction with the USACE "blanket theory" equations. In accordance with Bennett's (1946) general assumptions, the USACE method makes the following assumptions about seepage flow in the foundation: (1) Seepage may enter the pervious substratum at any point in the foreshore (either through riverside borrow pits and/or through the riverside top stratum), (2) flow through the top stratum is vertical, (3) flow through the pervious substratum is horizontal, (4) the levee and the portion of the top stratum beneath it are impervious, which means water is not allowed to flow through the levee, and (5) all seepage is laminar flow.

In order to use the USACE (2000) levee underseepage analysis approach, an engineer must first determine the general slope of the hydraulic gradient line in the foundation layer, $M$ (shown in Fig. 3), which is calculated using the equation:

$$
M=\frac{H}{x_{1}+L_{2}+x_{3}}
$$

where $H$ is the net head on the levee, $L_{2}$ is the base width of the levee, and $x_{1}$ and $x_{3}$ are the effective seepage entrance and exit points, respectively (these dimensions are shown in Fig. 3). In levee design following the USACE method, it is typical practice to use the variable " $c$ " to characterize the relative tendency for infiltration and exfiltration through the overlying confining blanket; not surprisingly, this factor is directly related to the leakage factor that was defined previously (Eq. (10)):

$$
c=\frac{1}{\lambda_{1}}=\sqrt{\frac{k_{b}}{k_{f} z_{b} d}}
$$

where $d$ is the thickness of the foundation layer, $k_{f}=k$ $=$ the permeability of the foundation layer, $z_{b}=z_{1}=$ the thickness of the semipervious blanket, and $k_{b}=k_{1}=$ the permeability of the semipervious blanket.

The relative magnitude of $x_{1}$ and $x_{3}$ are strongly affected by the magnitude of $c$ (e.g., Eqs. (13)-(14)). They are also affected by the length of the riverside and landside blankets $\left(L_{1}\right.$ and $\left.L_{3}\right)$, and the boundary conditions that are assumed. When performing levee underseepage analyses, two analysis boundary conditions are common, a no-flow condition at the boundary, which is commonly referred to as a "seepage block", or an applied head condition at the boundary, which is commonly referred to as a "seepage opening" (Fig. 3). These two boundary conditions correspond to the Case $7 \mathrm{~b}$ and Case $7 \mathrm{c}$ analysis conditions, respectively, that are described in Appendix B of the USACE levee design manual (USACE, 2000).

For the case where the riverside blanket and landside blanket soils are the same, and where $L_{1}$ and $L_{3}$ are finite distances to seepage blocks on the riverside and landside of the levee, respectively (Fig. 3), $x_{1}$ and $x_{3}$ can be calculated as follows (USACE, 2000, Case 7b):

$$
\begin{aligned}
& x_{1}=\frac{1}{c \tanh \left(c L_{1}\right)} \\
& x_{3}=\frac{1}{c \tanh \left(c L_{3}\right)}
\end{aligned}
$$




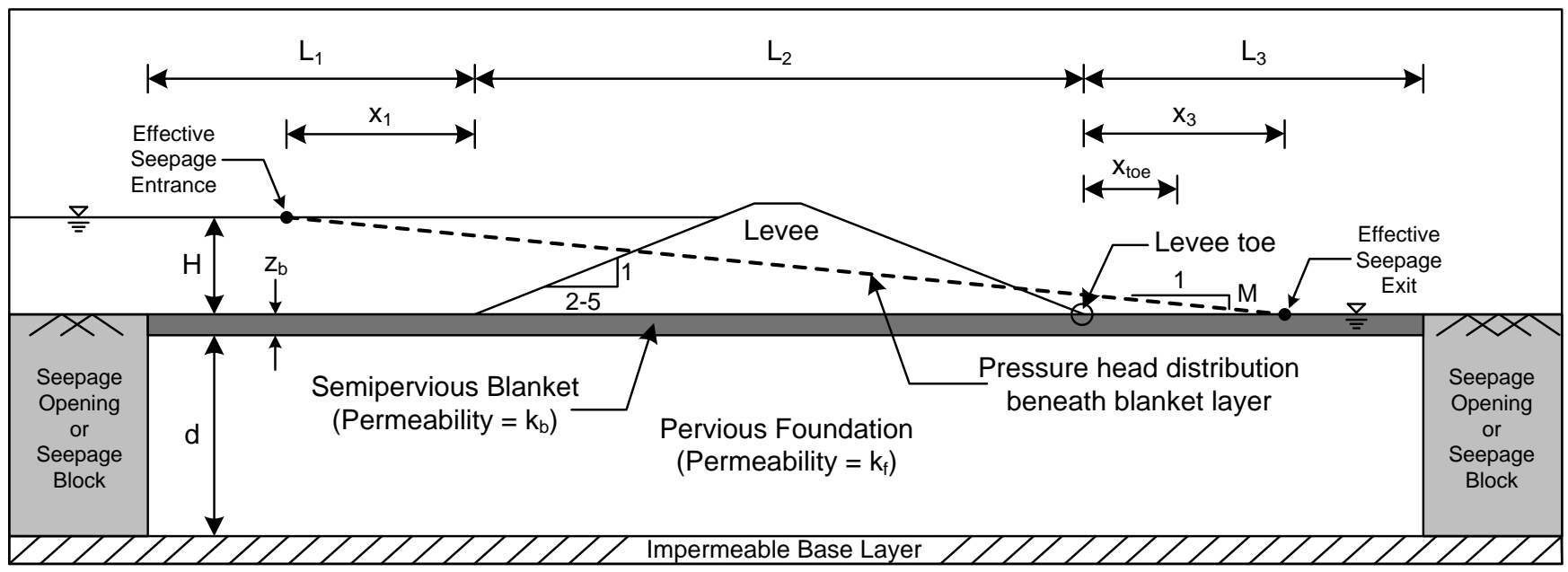

Fig. 3: An idealized levee cross-section that is used for underseepage analysis following the USACE "blanket theory" approach.

For the case where the riverside blanket and landside blanket soils are the same, and where $L_{1}$ and $L_{3}$ are finite distances to open seepage entrances and exits, respectively (Fig. 3), $x_{1}$ and $x_{3}$ can be calculated as follows (USACE, 2000, Case 7c):

$$
\begin{aligned}
& x_{1}=\frac{\tanh \left(c L_{1}\right)}{c} \\
& x_{3}=\frac{\tanh \left(c L_{3}\right)}{c}
\end{aligned}
$$

If the landside and riverside blankets are different, then different values for $c$ can be used in Eqs. (13) and (14) or Eqs. (15) and (16) to determine the appropriate values of $x_{1}$ and $x_{3}$. These equations can also be interchanged, e.g., if a user wants to model seepage opening (riverside) and seepage block (landside) boundary conditions, Eq. (15) should be used in conjunction with Eq. (14) to determine $x_{1}$ and $x_{3}$, respectively. Similarly, if a user wants to model seepage block (riverside) and seepage opening (landside) boundary conditions, then Eqs. (13) and (16) should be used.

If the distance to the seepage blocks or seepage openings is relatively large, then the assumed boundary conditions tend to have only a minor effect on the analysis results. In particular, when $L_{1}$ or $L_{3}$ is very large (e.g., has a value that approaches infinity), an assumption of infinite blanket length can reasonably be made. If this is the case, the hyperbolic tangent term in Eqs. (13)-(16) becomes 1, the boundary condition assumptions have a negligible effect, and $x_{1}$ and $x_{3}$ can be calculated as follows (USACE, 2000, Case 7a):

$$
x_{1}=x_{3}=\frac{1}{c}
$$

Once the slope of the hydraulic grade line has been determined, levee designers typically focus on two critical design parameters of interest: (1) the head beneath the blanket layer on the landside of the levee, which, if it is too large, can cause heaving and cracking of the blanket and internal erosion and piping of the foundation soils (e.g., sand boils), and (2) the quantity of seepage passing beneath the levee through the foundation layer. Of particular concern is the pressure head beneath the blanket at the landside levee toe $\left(h_{\text {toe }}\right)$, which is the highest pressure head on the landside of the levee. Following the USACE (2000) approach, this head can be calculated using the equation:

$$
h_{\text {toe }}=M x_{3}
$$

Although often shown to the contrary in many sketches (including in the USACE levee design manual itself), the slope of the hydraulic grade line beneath the levee $(M)$ cannot be extrapolated outside of the levee footprint to determine pressure head values beneath the blanket layer. In particular, a linear extrapolation of the hydraulic grade line beneath the levee for distances beyond the landside levee toe will lead to unconservative calculations of pressure head beneath the blanket layer. Recognizing this, the USACE (2000) manual recommends that the following equations be used to determine head values beneath the blanket layer at landside distances beyond the levee toe, for situations where either a landside seepage block (Eq. (19)) or a landside seepage opening (Eq. (20)) is present:

$$
\begin{aligned}
& h_{x_{-} t o e}=h_{\text {toe }} \frac{\cosh \left[c\left(L_{3}-x_{t o e}\right)\right]}{\cosh \left[c L_{3}\right]} \\
& h_{x_{-} t o e}=h_{t o e} \frac{\sinh \left[c\left(L_{3}-x_{t o e}\right)\right]}{\sinh \left[c L_{3}\right]}
\end{aligned}
$$

where $h_{x_{-} t o e}$ is the pressure head beneath the blanket at a specified distance beyond the landside levee toe, and $x_{t o e}$ is the distance of interest beyond the landside levee toe (Fig. 3). No equations are presented in the USACE (2000) 
levee manual for determining the distribution of pressure head beneath the blanket on the riverside of the levee. This is because blanket uplift and internal erosion will not occur in this zone, given the direction of seepage flow beneath the levee.

The hyperbolic functions in Eqs. (19) and (20) are necessary because the hydraulic gradient through the blanket layer is highest near the toe of the levee and decreases with distance away from the levee. Consequently, the seepage though the blanket is greatest at the levee toe, and smaller at distances away from the levee. This behavior results in a curved shape of the piezometric surface on the landside of the levee, not a straight line as is sometimes mistakenly assumed (the piezometric surface is a straight line only directly beneath the levee, in the zone where no seepage is entering or exiting the semiconfined foundation layer).

Following the USACE (2000) approach, the quantity of seepage $(Q)$ passing through the foundation layer for a levee cross-section of unit width (in units of $\mathrm{m}^{3} /$ day $/ \mathrm{m}$ ) can be calculated using the following equation:

$$
Q=M k_{f} d
$$

\section{Derivation of an Analytical Approach for Levee Underseepage Analysis}

As noted in the introduction, one of the goals of this paper is to provide a synopsis of a derivation of a series of closedform analytical equations for levee underseepage analysis that are based on a general confined flow approach that originates from groundwater modeling theory. As noted previously, in situations where flow beneath an earthen dam or levee is confined by a lower permeability blanket layer (e.g., Figs. 3 and 4), Laplace's steady-state confined groundwater flow equation (Eq. (1)) can be utilized. In these situations, the more permeable aquifer through which water flows is referred to as the foundation, and the less permeable confining layer where water is infiltrating or exfiltrating is commonly referred to as the semipervious blanket (Fig. 4). As the nature of the seepage flow is different on the riverside of the levee, beneath the levee, and on the landside of the levee, it is appropriate to divide the levee foundation into three parts: Zone 1, Zone 2, and Zone 3 (Fig. 4).

In order to derive the desired closed-form approach for levee underseepage analysis, it is necessary to make a few simplifying assumptions that are appropriate for levee design. To allow for comparison with the USACE (2000) design approach, the assumptions that are made in this derivation will be the same as those that are made for the USACE (2000) design approach. Continuing the groundwater flow solution derivation from Eqs. (8) and (9) above:

For purposes of levee underseepage analysis, the base of the foundation layer is assumed to be impermeable, which means that $k_{2}=0$; typically, all heads are measured from this impermeable layer datum (Fig. 4). For a structure that has a relatively uniform cross section perpendicular to the $y$-axis (e.g., one that lends itself nicely to $2-\mathrm{D}$ analysis), there will be no variation in head in the $y$-direction, and thus the flow will be one-dimensional. Consequently, in Zones 1 and 3 (where leakage is occurring), for a uniform levee cross section with an impermeable base layer, Eqs. (8) and (9) reduce to:

$$
\frac{d^{2} h}{d x^{2}}=\frac{h-h_{1}}{k m_{1} d}=\frac{h-h_{1}}{\lambda_{1}^{2}}
$$

where $h-h_{1}=$ the difference between the total head in the foundation and the total head acting above the semipervious blanket, $\lambda_{1}=\sqrt{k_{f} z_{b} d / k_{b}}, k_{f}=k=$ permeability of the foundation, $z_{b}=z_{1}=$ the thickness of the semipervious blanket, and $k_{b}=k_{1}=$ the permeability of the semipervious blanket.

Assuming that $h_{1}$ is a constant, which is typical for levee applications, the general solution to the second-order linear ordinary differential equation presented in Eq. (22) has the following form:

$$
h-h_{1}=A e^{x / \lambda}+B e^{-x / \lambda}
$$

where $A$ and $B$ are unknown constants which are solved when the specific boundary conditions are known. As noted, Eq. (23) is applicable on the riverside of the levee (Zone 1) and on the landside of the levee (Zone 3), in areas where leakage is occurring into and out of the confined foundation layer (Fig. 4). Immediately beneath the levee (Zone 2), leakage is not allowed to occur, and the following equations can be used to determine the head distribution:

$$
\begin{gathered}
\frac{d^{2} h}{d x^{2}}=0 \\
h=C x+D
\end{gathered}
$$

where $C$ and $D$ are unknown constants which are solved when the specific boundary conditions are known.

In order to solve Eqs. (23) and (25), a reference coordinate system must be established; for the equations that are derived here, the horizontal distance $x$ is taken to be zero at the centerline of the levee, with riverside $x$ distances being negative, and landside $x$-distances being positive (Fig. 4). Boundary conditions for Zones 1-3 can then be applied, which allows the differential equation solutions above (Eqs. (23) and (25)) to be solved separately for each zone to yield an equation for the head beneath the blanket layer $\left(h_{x}\right)$ as a function of horizontal distance from the center of the levee $(x)$. As noted previously, two analysis boundary conditions are common in levee underseepage analyses, a no-flow condition at the boundary (e.g., $d h / d x=0$ ), which is commonly referred to as a "seepage block", or an applied head condition at the boundary (e.g., $h=$ known head value), which is commonly referred to as a "seepage opening" (Fig. 4). These two boundary conditions are the same as those that are used in the USACE 


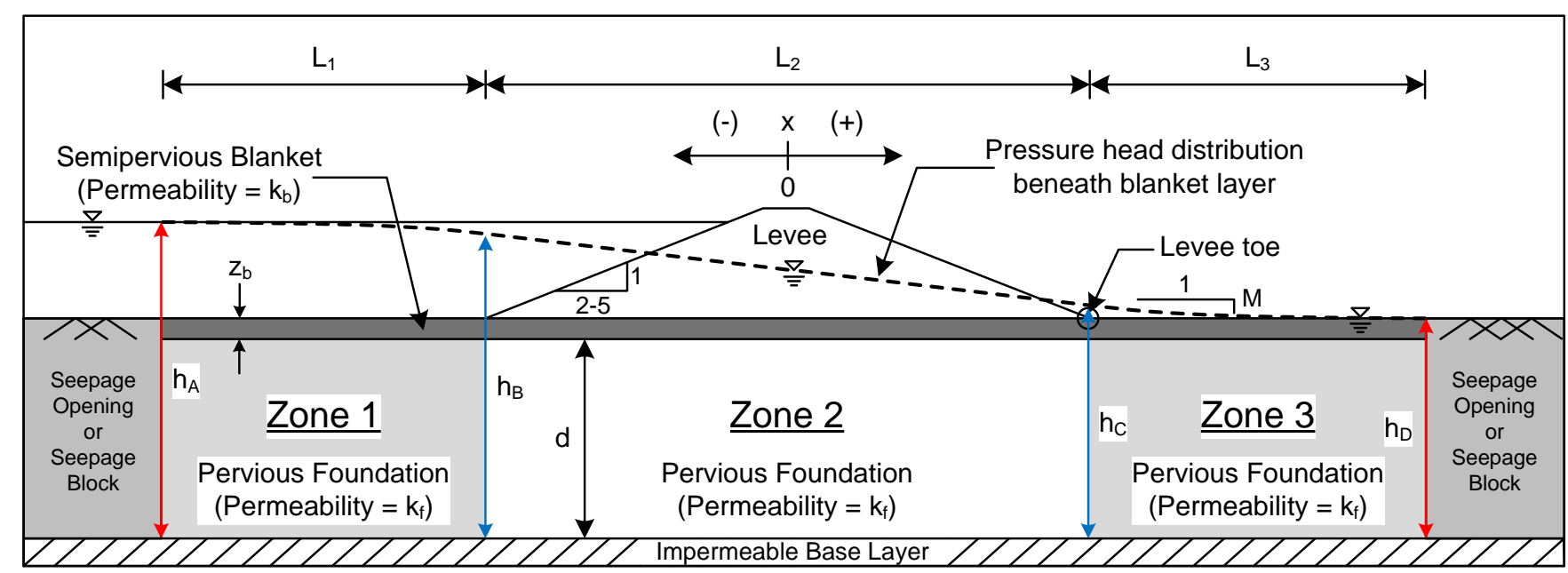

Fig. 4: An idealized levee cross-section that is used for underseepage analysis following the analytical approach that is derived in Section 4.

levee design method that is described in the previous section.

A step-by-step derivation of the analytical head line equations that result from this process is available in Benjasupattananan (2012); for brevity, only the final equations that result will be presented here. In Zone 1, Eq. (26) should be used to determine $h_{x}$ if a seepage block is present on the riverside of the levee. Eq. (27) should be used for Zone 1 if a seepage opening is present on the riverside of the levee.

$$
\begin{aligned}
& h_{x}=\left(h_{B}-h_{A}\right) \frac{\cosh \left(\frac{2 x+2 L_{1}+L_{2}}{2 \lambda}\right)}{\cosh \left(\frac{L_{1}}{\lambda}\right)}+h_{A} \\
& h_{x}=\left(h_{B}-h_{A}\right) \frac{\sinh \left(\frac{2 x+2 L_{1}+L_{2}}{2 \lambda}\right)}{\sinh \left(\frac{L_{1}}{\lambda}\right)}+h_{A}
\end{aligned}
$$

In Zone 2, Eq. (28) should be used to determine $h_{x}$ :

$$
h_{x}=\frac{\left(h_{B}+h_{C}\right)}{2}-\frac{\left(h_{B}-h_{C}\right) x}{L_{2}}
$$

In Zone 3, Eq. (29) should be used to determine $h_{x}$ if a seepage block is present on the landside of the levee. Eq. (30) should be used for Zone 3 if a seepage opening is present on the landside of the levee.

$$
\begin{aligned}
& h_{x}=\left(h_{C}-h_{D}\right) \frac{\cosh \left(\frac{2 L_{3}+L_{2}-2 x}{2 \lambda}\right)}{\cosh \left(\frac{L_{3}}{\lambda}\right)}+h_{D} \\
& h_{x}=\left(h_{C}-h_{D}\right) \frac{\sinh \left(\frac{2 L_{3}+L_{2}-2 x}{2 \lambda}\right)}{\sinh \left(\frac{L_{3}}{\lambda}\right)}+h_{D}
\end{aligned}
$$

The total quantity of seepage $(Q)$ passing through each zone in the foundation layer can be calculated separately for Zones 1-3, for a levee cross-section of unit width (in units of $\mathrm{m}^{3} /$ day $/ \mathrm{m}$ ), using Eqs. (31)-(33), respectively:

$$
\begin{gathered}
Q_{1}=k_{f} d\left(\frac{h_{A}-h_{B}}{\lambda}\right) C_{i} \\
Q_{2}=k_{f} d\left(\frac{h_{B}-h_{C}}{L_{2}}\right) \\
Q_{3}=k_{f} d\left(\frac{h_{C}-h_{D}}{\lambda}\right) C_{i}
\end{gathered}
$$

where the $C_{i}$ in Eqs. (31) and (33) describes a term that should be added to these equations to account for the effect of the assumed boundary conditions. If a riverside block is present, the term $C_{i}=C_{2}=\tanh \left(L_{1} / \lambda\right)$ should be used in Eq. (31). If a riverside opening is present, the term $C_{i}=C_{1}=1 / \tanh \left(L_{1} / \lambda\right)$ should be used in Eq. (31). If a landside block is present, the term $C_{i}=C_{4}=\tanh \left(L_{3} / \lambda\right)$ should be used in Eq. (33). If a landside opening is present, the term $C_{i}=C_{3}=1 / \tanh \left(L_{3} / \lambda\right)$ should be used in Eq. (33). These terms are the same as those that are used in Table 1 for calculating the intermediate $h_{B}$ and $h_{C}$ values.

For a specific levee underseepage problem, the position of the head line in any one of the three foundation zones is affected by the seepage behavior in the other two foundation zones. In order to include this effect in the analytical solution, seepage continuity needs to applied at the interface between each zone. Specifically, the seepage through Zone 1 has to be equal to the seepage through Zone 2, and the seepage through Zone 2 has to be equal to the seepage through Zone 3. By setting Eq. (31) equal to Eq. (32), and Eq. (32) equal to Eq. (33), the appropriate values of $h_{B}$ and $h_{C}$ can be determined for each boundary condition case. Four possible combinations of boundary conditions may be selected, each of which have a different set of equations 
Table 1: Equations for Calculating $h_{B}$ and $h_{C}$ for Seepage Block/Opening Conditions on Either the Riverside or Landside of the Levee

\begin{tabular}{|c|c|c|c|c|c|c|}
\hline \multirow[t]{2}{*}{ Conditions } & \multicolumn{6}{|c|}{ Riverside } \\
\hline & \multicolumn{3}{|l|}{ Block } & \multicolumn{3}{|l|}{ Open } \\
\hline \multicolumn{7}{|l|}{ Landside } \\
\hline Block & $h_{B}=$ & {$\left[\frac{\left(h_{A}+h_{D}\right)+\left(L_{2}-\lambda C_{1}+\lambda C_{3}\right)\left(h_{A} / \lambda C_{1}\right)}{\left(L_{2}+\lambda C_{1}+\lambda C_{3}\right)}\right]$} & $\lambda C_{1}$ & $h_{B}=$ & {$\left[\frac{\left(h_{A}+h_{D}\right)+\left(L_{2}-\lambda C_{2}+\lambda C_{3}\right)\left(h_{A} / \lambda C_{2}\right)}{\left(L_{2}+\lambda C_{2}+\lambda C_{3}\right)}\right.$} & $\lambda C_{2}$ \\
\hline \multirow{3}{*}{ Open } & $h_{C}=$ & {$\left[\frac{\left(h_{A}+h_{D}\right)+\left(L_{2}+\lambda C_{1}-\lambda C_{3}\right)\left(h_{D} / \lambda C_{3}\right)}{\left(L_{2}+\lambda C_{1}+\lambda C_{3}\right)}\right]$} & $\lambda C_{3}$ & $h_{C}=$ & {$\left[\frac{\left(h_{A}+h_{D}\right)+\left(L_{2}+\lambda C_{2}-\lambda C_{3}\right)\left(h_{D} / \lambda C_{3}\right)}{\left(L_{2}+\lambda C_{2}+\lambda C_{3}\right)}\right.$} & $\lambda C_{3}$ \\
\hline & $h_{B}=$ & {$\left[\frac{\left(h_{A}+h_{D}\right)+\left(L_{2}-\lambda C_{1}+\lambda C_{4}\right)\left(h_{A} / \lambda C_{1}\right)}{\left(L_{2}+\lambda C_{1}+\lambda C_{4}\right)}\right]$} & $\lambda C_{1}$ & $h_{B}=$ & {$\left[\frac{\left(h_{A}+h_{D}\right)+\left(L_{2}-\lambda C_{2}+\lambda C_{4}\right)\left(h_{A} / \lambda C_{2}\right)}{\left(L_{2}+\lambda C_{2}+\lambda C_{4}\right)}\right.$} & $\lambda C_{2}$ \\
\hline & $h_{C}=$ & {$\left[\frac{\left(h_{A}+h_{D}\right)+\left(L_{2}+\lambda C_{1}-\lambda C_{4}\right)\left(h_{D} / \lambda C_{4}\right)}{\left(L_{2}+\lambda C_{1}+\lambda C_{4}\right)}\right]$} & $\lambda C_{4}$ & $h_{C}=$ & {$\left[\frac{\left(h_{A}+h_{D}\right)+\left(L_{2}+\lambda C_{2}-\lambda C_{4}\right)\left(h_{D} / \lambda C_{4}\right)}{\left(L_{2}+\lambda C_{2}+\lambda C_{4}\right)}\right.$} & $\lambda C_{4}$ \\
\hline Coefficients & $C_{1}=1$ & $/ \tanh \left(L_{1} / \lambda\right) \quad C_{2}=\tanh \left(L_{1} / \lambda\right)$ & & $C_{3}=1$ & $/ \tanh \left(L_{3} / \lambda\right) \quad C_{4}=\tanh \left(L_{3} / \lambda\right)$ & \\
\hline
\end{tabular}

for determining $h_{B}$ and $h_{C}$ : (1) seepage block riverside and seepage block landside, (2) seepage opening riverside and seepage block landside, (3) seepage block riverside and seepage opening landside, and (4) seepage opening riverside and seepage opening landside. The associated equations for $h_{B}$ and $h_{C}$ that result for each of these boundary condition combinations are provided in Table 1.

In order to use the analytical approach that is presented in this section, it is first necessary to define the geometry of the problem, and the associated permeabilities of the foundation and blanket layers. The riverside and landside boundary conditions at the lateral extents of the problem also need to be defined. Using the appropriate boundary conditions, values of $h_{B}$ and $h_{C}$ can be calculated using the equations that are presented in Table 1 . The resulting $h_{B}$ and $h_{C}$ values are then used with either Eq. (26) or (27) to define the position of the head line in Zone 1, with Eq. (28) to define the position of the head line in Zone 2, and with either Eq. (29) or (30) to define the position of the head line in Zone 3. If these three lines are connected, the total distribution of head beneath the blanket layer can be drawn directly. For design purposes, the head at the levee toe $\left(h_{\text {toe }}\right)$ is equal to $h_{C}$, and the quantity of seepage passing through the foundation layer $(Q)$ can be calculated using either Eqs. (31), (32) or (33).

\section{Application of Analytical Model to a Simple Levee Underseepage Case}

In order to examine how the analytical solution that is described in the previous section works, it is instructive to examine the behavior of a simple representative case (Fig. 5). As shown, a homogeneous, low-permeability isotropic levee, $10 \mathrm{~m}$ high, with a $6 \mathrm{~m}$ wide crest and 2.5:1 side slopes is constructed on top of a two-layer foundation. The foundation consists of a long, finite-length semipervious blanket that is $2 \mathrm{~m}$ thick, that overlies a more pervious foundation layer that has a thickness of $32 \mathrm{~m}$. At the design flood level, the levee is intended to hold back $8 \mathrm{~m}$ of water. For this case, $L_{1}=160 \mathrm{~m}, L_{2}=56 \mathrm{~m}, L_{3}=160$ $\mathrm{m}, H=8 \mathrm{~m}, z_{b}=2 \mathrm{~m}$, and $d=32 \mathrm{~m}$. A relatively high permeability of $10^{-1} \mathrm{~cm} / \mathrm{s}$ was selected for the foundation soil $\left(k_{f}=10^{-1} \mathrm{~cm} / \mathrm{s}\right)$, and the permeability of the blanket layer soil $\left(k_{b}\right)$ was varied parametrically from $10^{-9} \mathrm{~cm} / \mathrm{s}$ to $10^{-1} \mathrm{~cm} / \mathrm{s}$ (a range of low to high permeabilities).

From the information that is given for this case, it is possible to use both the analytical equations that are derived in this paper as well as the US Army Corps of Engineers levee underseepage analysis approach (USACE, 2000) to determine the head beneath the blanket layer at the downstream levee toe $\left(h_{t o e}\right)$ and the quantity of seepage beneath the levee $(Q)$ per unit time. A comparison of the results between the two models for $h_{\text {toe }}$ and $Q$ is provided in Fig. 6; results are presented for varying blanket layer permeabilities, in order to show the effect that this parameter has on model results. As can be clearly observed, the two models yield results that are in exact agreement with each other, for both $h_{t o e}$ and $Q$, over the entire range of permeability values and boundary conditions that were examined in this study. These results provide validation for both the equations that are presented in this paper and the conventional USACE analytical design approach.

Upon closer examination, the results between these two analytical approaches are in exact agreement because both these models use the same general assumptions in their derivation (Benjasupattananan, 2012). The key differences between the analytical solution that is presented in this paper and the USACE approach are: (1) the way that the design equations are presented (e.g., the functional forms that are used, and the fact that results are calculated using total head terms rather than the net head on the levee), and (2) the use of a single coordinate system that has its origin at the centerline of the levee (analytical equations), rather than the use of multiple (different) coordinate sys- 


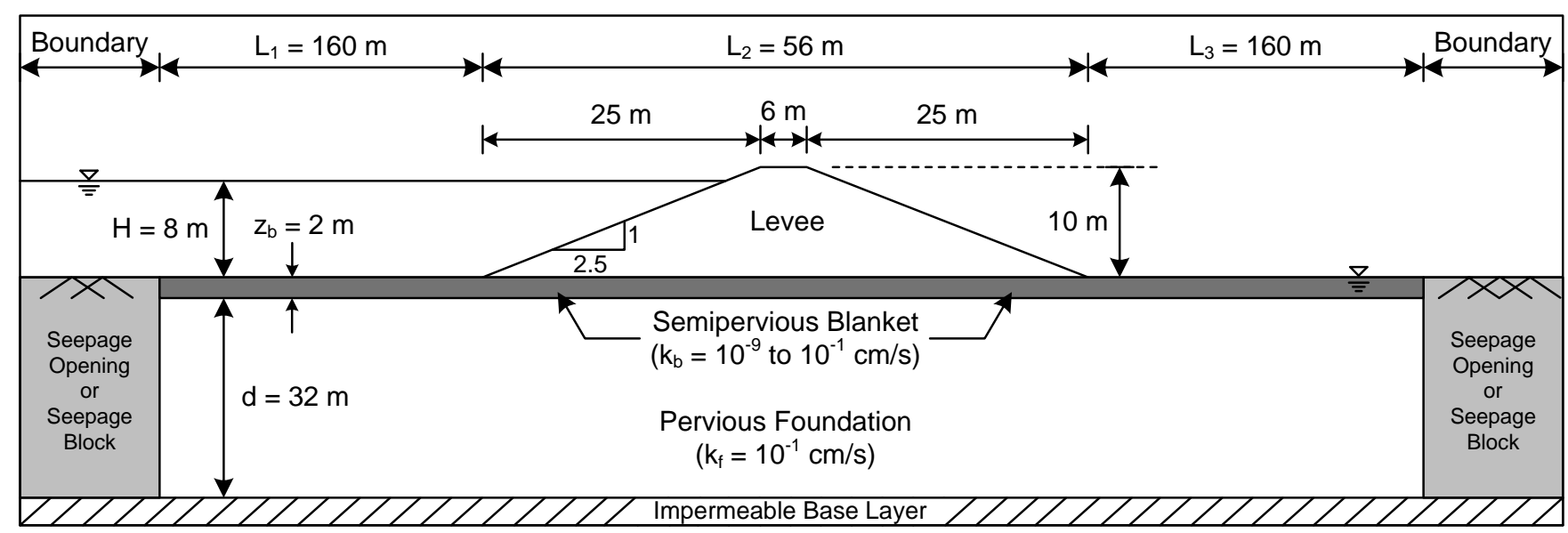

Fig. 5: A simple levee underseepage case (not to scale).
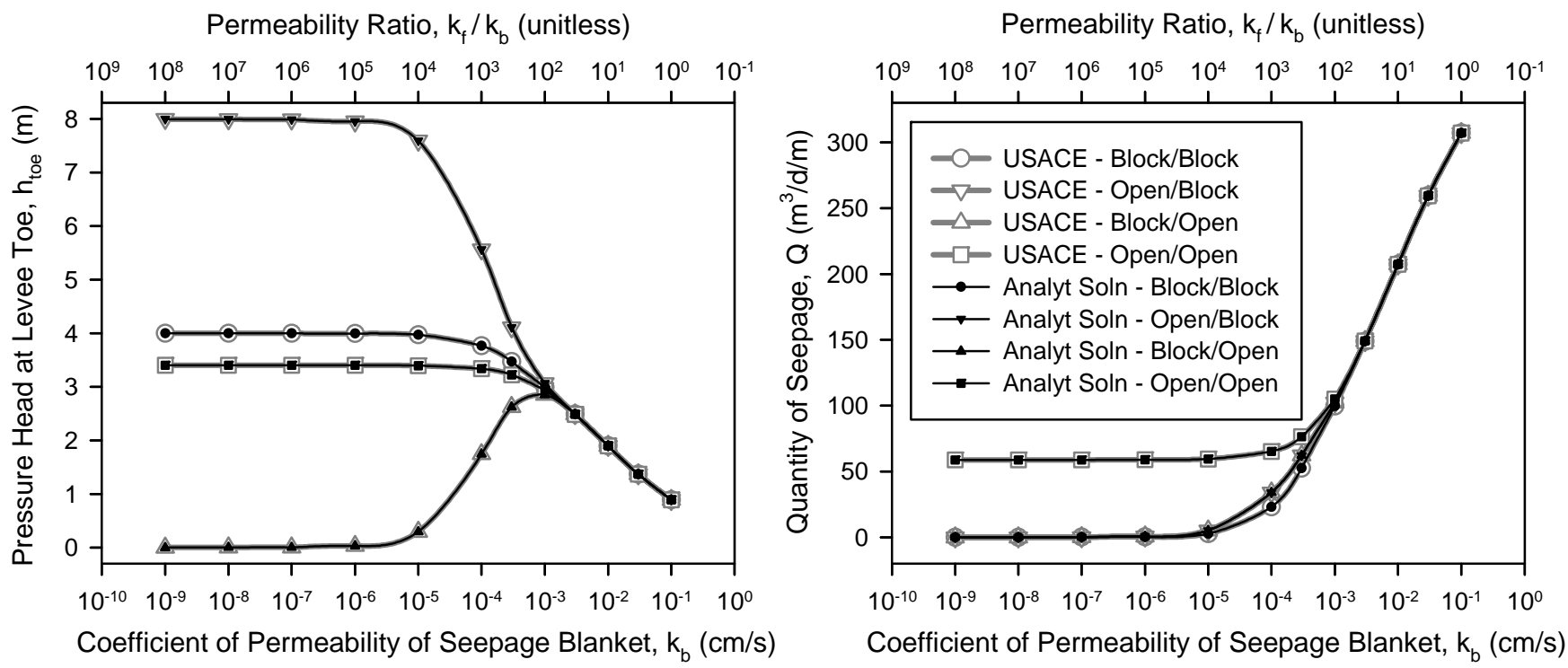

Fig. 6: A comparison of results from the analytical equations that are presented in this paper and the USACE (2000) levee underseepage analysis equations, for "seepage block" and "seepage opening" boundary conditions. Results are presented for the pressure head beneath the blanket layer at the levee toe and the quantity of seepage beneath the levee per unit time, for varying blanket permeabilities.

tems in the derivation (USACE approach). The second of these factors is particularly significant, as the approach that is presented here provides a framework for calculation that can also be extended to curved levee alignments, an aspect which will be discussed in more detail in a future publication. To illustrate the similarities and differences between these two derivation approaches, Benjasupattananan (2012) also presents a complete derivation of the USACE (2000) equations. Another key difference between the two approaches is that the USACE (2000) approach does not include any equations for defining the flow behavior beneath the blanket layer on the riverside of the levee, while equations for defining the head line for all three seepage zones are presented with the analytical equations that are given here.

The general usefulness of the equations that are presented herein is only limited by the assumptions that are used in their derivation, in particular the need for constant layer thicknesses and simplified geometry. In situations where the foundation layer thickness and/or blanket thickness are not fairly consistent, the use of the proposed equations will not produce results that are as reliable as finite element analyses that take into account the nature of the varying geology. Simplified "blanket-theory" equations of the type that are derived herein also do not work well for certain multi-layer geologies that cannot be reasonably represented using a two layer system (e.g. Gabr et al., 1996); finite element analyses or the three-layer modeling approach suggested by Gabr et al. (1996) are recommended in this situation. A significant benefit of the equations that are derived herein is that the associated closed-form solutions are easy to use and consequently allow for rapid assessment of a problem via parametric studies. They are also well-suited to reliability analyses, especially for prob- 


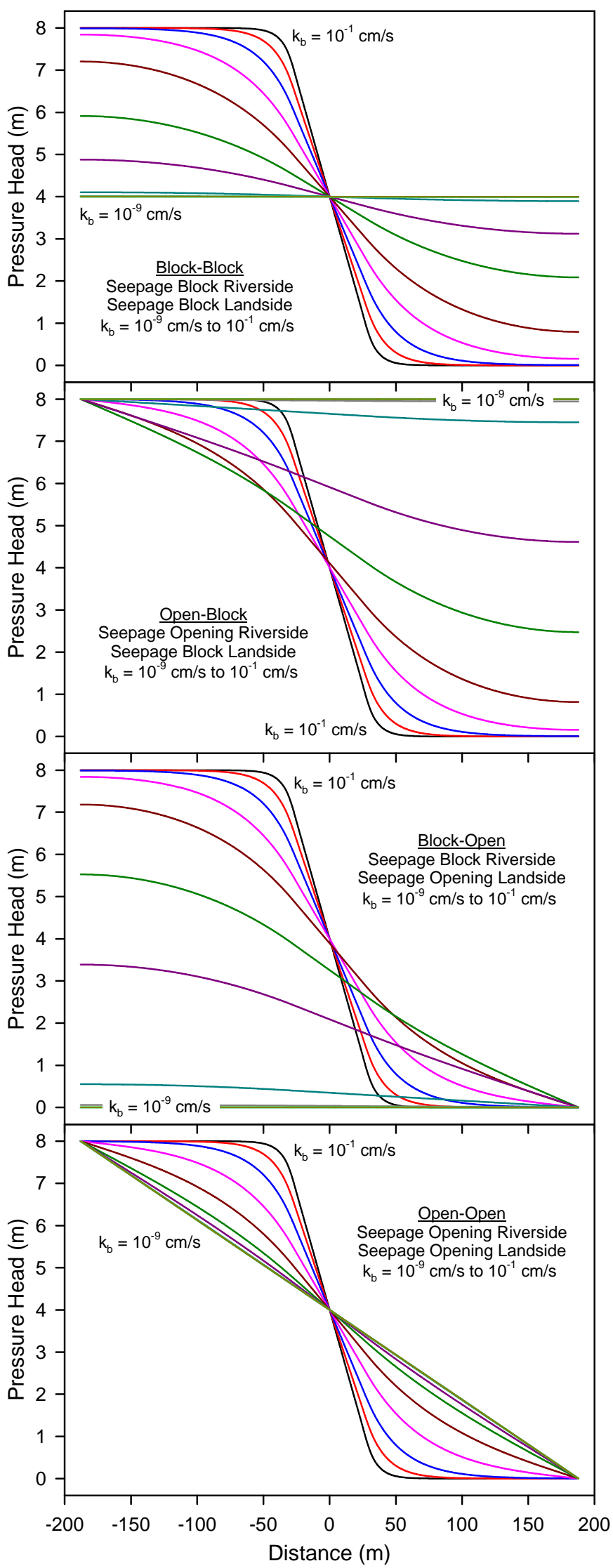

Fig. 7: The distribution of pressure head beneath the semipervious blanket layer, for various blanket layer permeabilities and boundary condition combinations. lems that require computationally expensive Monte Carlo simulations.

\subsection{The Interaction Between Blanket Layer Permeability $\left(k_{b}\right)$ and Boundary Conditions}

For each of the example cases that are shown in Fig. 6, it is also relatively straightforward to draw the associated distribution of head beneath the semipervious blanket layer for the entire foundation profile (Fig. 7), using the analytical equations that are presented herein (Eqs. (26)-(30)). A key advantage of the equations that are presented in this paper over those that are utilized in the USACE (2000) method is that the head line distribution beneath the blanket layer can be presented on the riverside of the levee, beneath the levee, and on the landside of the levee (in contrast, the USACE equations do not define a continuous headline distribution over the entire $x$ domain). This head line determination allows for a more detailed understanding of the flow behavior in the foundation layer at all locations in the solution domain.

In Fig. 7, results are presented for blanket permeabilties ranging from $10^{-1} \mathrm{~cm} / \mathrm{s}$ to $10^{-9} \mathrm{~cm} / \mathrm{s}$, for the four possible boundary condition combinations: (1) a seepage block on the riverside of the levee and a seepage block on the landside of the levee, (2) a seepage opening riverside and a seepage block landside, (3) a seepage block riverside and a seepage opening landside, and (4) a seepage opening riverside and a seepage opening landside. As shown in Fig. 7, if the semipervious blanket layer that is selected is relatively permeable, then the boundary conditions that are selected tend to not have a significant effect on the results, since most of the change in head that is occurring is happening close to the levee, at distances away from the boundary. However, in contrast, if the semipervious blanket layer is relatively impermeable, then the boundary conditions that are selected have a very significant effect on the results. As shown in Fig. 6, if one focuses on the head at the levee toe $\left(h_{t o e}\right)$ and the seepage quantity passing beneath the levee $(Q)$ as design parameters of interest, then the boundary conditions begin to have a significant effect at blanket permeabilities less than $10^{-3} \mathrm{~cm} / \mathrm{s}$ (at a foundation to blanket permeability ratio greater than 100). This behavior is generally consistent with observations that have been made by other researchers in this area (e.g. USACE, 1956a, 1956b).

\subsection{A Parametric Study: Varying $k_{f}, d$, and $z_{b}$}

In order to exercise the analytical model that was developed, this section describes a series of parametric analyses that were performed to illustrate the effect of varying $k_{f}$, $d$, and $z_{b}$ on the model results. For each of the parametric studies that was conducted, results are presented for a range of $k_{b}$ values (from $10^{-1} \mathrm{~cm} / \mathrm{s}$ to $10^{-9} \mathrm{~cm} / \mathrm{s}$ ), in a similar fashion as Fig. 6. In order to assess the effect of changes in the foundation soil permeability, the $k_{f}$ values were varied as follows: 1, 0.1, 0.01, 0.001, and 0.0001 $\mathrm{cm} / \mathrm{s}$. Results were discarded for any cases where the blanket layer permeability ended up greater than the founda- 
tion layer permeability, as this is not how confined aquifer models are supposed to work. In order to assess the effect of variations in the thickness of the foundation layer, the $d$ values were varied as follows: $8,16,32,40,48,56$, and 64 $\mathrm{m}$. In order to assess the effect of variations in the thickness of the blanket layer, the $z_{b}$ values were varied as follows: $0.5,1,2,4,8$, and $16 \mathrm{~m}$. For each set of these parametric analyses that were performed, the variable of interest was changed while keeping all other parameters the same as those in the base analysis case that was defined earlier.

The resulting parametric studies show model sensitivity to a variety of input parameters, including: $k_{b}, k_{f}$, $d, z_{b}$, and the various boundary condition configurations. Numerous curves result from the parametric studies that were performed; however, in an attempt to clarify this significant amount of data and enhance the visualization of the parametric study results, it is useful to try to develop a single set of plots that shows the overall findings from all of the analyses. Conveniently, the parametric study results show that the problem is a scalable one for a number of the model input parameters - this allows for more convenient "normalization" of the results. Fig. 8 provides a comparison of results from the parametric studies where $k_{f}, d$, and $z_{b}$ were varied, for different "seepage block" and "seepage opening" boundary conditions. The results shown in this figure are presented for the pressure head beneath the blanket layer at the levee toe and the quantity of seepage beneath the levee per unit time, for varying blanket permeabilities.

As shown in Fig. 8, if the parametric study results are plotted versus the leakage factor (instead of the blanket permeability), the results from the different $k_{f}, d$, and $z_{b}$ analyses fall on exactly the same curve (e.g., the problem is a scalable one). In order to yield identical curves, it is also necessary to normalize the seepage quantity $(Q)$ by dividing this quantity by the product of $k_{f}$ and $d$. If the results from the parametric study are plotted in this fashion, it can be observed that different curves exist for the four possible boundary condition combinations; further, it can also be observed that the general shape and relative positioning of the curves are exactly the same as what is shown in Fig. 6, even as the input values in the model are changing. From this figure, two trends of particular interest can be observed:

1. The first trend of interest is that, at leakage values less than 100 or so (e.g., $\lambda<100$ ), the curves for all four boundary condition combinations join together, yielding values for $h_{t o e}$ and $Q$ that are relatively identical, independent of the boundary conditions that are applied in the analysis. This observation is significant, as it means that, for this particular parametric study, the assumed boundary conditions have no significant effect on the model results if the leakage value in the model is less than 100 .

2 . The second trend of interest is that, at leakage values greater than about 2500 or so (e.g., $\lambda>2500$ ) the curves for all four boundary condition cases level off into relatively horizontal lines. Beyond this point (e.g., for all higher values of $\lambda$ ), it is reasonable to assume that the semipermeable blanket is in fact relatively impermeable in its behavior with respect to the overall levee underseepage that is occurring.

It should be noted that the two values of $\lambda$ identified above are unique for this particular example problem. That is, for different values of $H, L_{1}, L_{2}$, and $L_{3}$, the associated values of $\lambda$ that correspond to a "no boundary condition effect" or an "impermeable blanket" layer would be different. However, the general shape of the curves shown in Fig. 8 would still be observed for other reasonable levee geometries. If a user wants to identify whether or not their levee blanket layer can be considered to be impermeable (e.g., Case 2, 3, or 4 in the USACE manual), or if they want to assess whether or not their boundary condition assumptions may be having an effect on their model results (e.g., Case $7 \mathrm{a}, 7 \mathrm{~b}$, or $7 \mathrm{c}$ in the USACE manual), performing a parametric study like that shown in Fig. 8 will allow this question to be answered. This type of parametric study is easy to implement using the equations that are presented in this paper with a computer spreadsheet program.

\section{Summary and Conclusions}

This paper provides a synopsis of a derivation of a series of closed-form "blanket theory" analytical equations that can be used to perform a levee underseepage analysis. This derivation starts from a generic confined flow analytical solution, of the type that is common in groundwater flow analyses. The solution is then extended to simulate semiconfined flow beneath a levee in a shallow aquifer. Equations are presented for calculating total head and seepage quantity values for different model boundary conditions. A typical example problem is used to compare the analytical equations that are derived with the analytical equations that are presented in the US Army Corps of Engineers (USACE) levee design manual. The results provide validation for both the equations that are presented and the conventional USACE analytical design approach. The results from the example problem that is presented, coupled with the results from additional parametric analyses that were performed, led the authors to the following two conclusions:

1. For semipervious blanket layers that are relatively permeable, the boundary conditions that are selected tend to not have a significant effect on the results, since most of the change in head that is occurring is happening close to the levee, at distances away from the boundary. However, for semipervious blanket layers that are relatively impermeable, the boundary conditions that are selected have a very significant effect on the results. This effect is illustrated in Figs. 6 and 7; for the example problem that is presented, the boundary conditions begin to have a significant effect at blanket permeabilities less than $10^{-3}$ $\mathrm{cm} / \mathrm{s}$ (at a foundation to blanket permeability ratio greater than 100). Consequently, four critical boundary condition combinations are identified for the blanket layers on the riverside and landside of the levee, respectively: block-block, open-block, block-open, and 

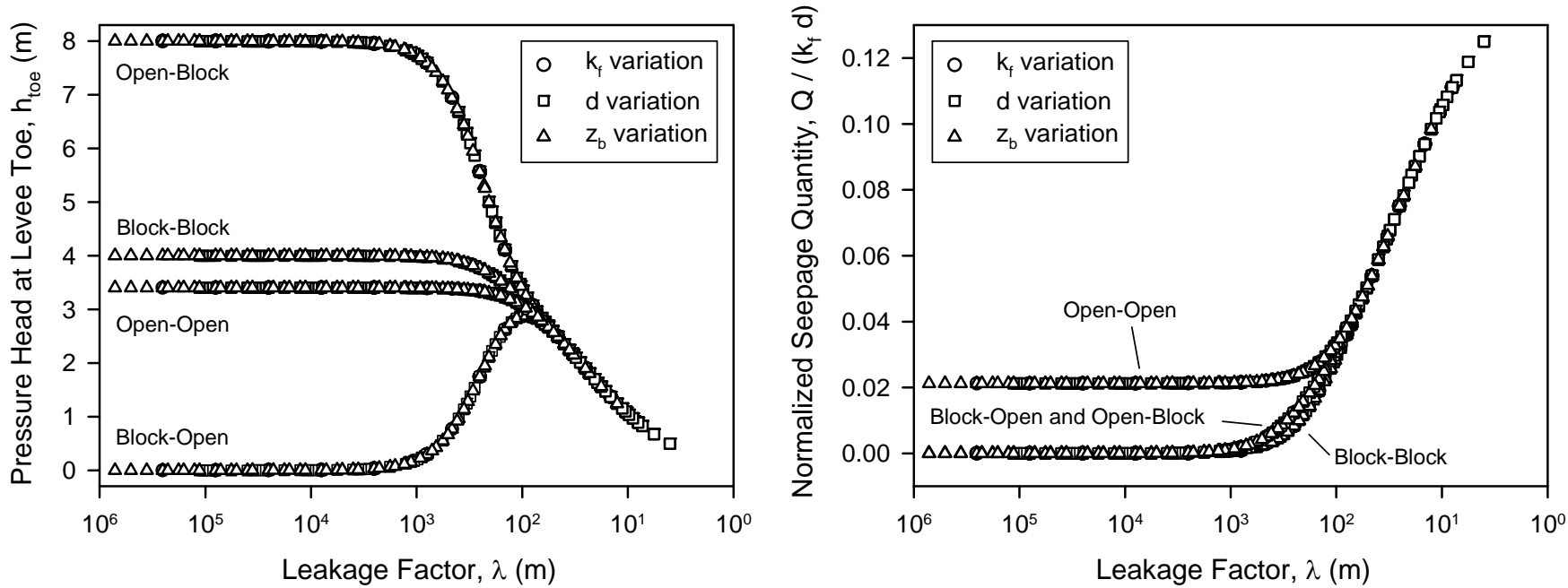

Fig. 8: A comparison of results from parametric studies where $k_{f}, d$, and $z_{b}$ were varied, for different "seepage block" and "seepage opening" boundary conditions. Results are presented for the pressure head beneath the blanket layer at the levee toe and the quantity of seepage beneath the levee per unit time, for varying blanket permeabilities.

open-open (where a seepage "block" corresponds to a no-flow condition at the boundary (e.g., $d h / d x=0$ ), and a seepage "opening" corresponds to an applied head condition at the boundary (e.g., $h=$ known head value)).

2. Using the analytical equations that were derived, it was discovered that the levee underseepage analysis results are sensitive to changes in any of the input parameters. However, for a number of the model input parameters (e.g., $k_{b}, k_{f}, d$, and $z_{b}$ ) the problem is a "fully scalable" one. This means that the results can be "normalized" to a single family of curves for different "seepage block" and "seepage opening" boundary conditions. As shown in Fig. 8, if the parametric study results are plotted versus the leakage factor (instead of the blanket permeability or foundation-to-blanket permeability ratio), the values of head at the levee toe $\left(h_{\text {toe }}\right)$ that result from the different $k_{f}, d$, and $z_{b}$ analyses fall on exactly the same curve. For the seepage quantity $(Q)$, it also is necessary to normalize $Q$ by dividing this quantity by the product of $k_{f}$ and $d$ to achieve normalization.

Taken together, the analytical equations that are presented herein are a practical tool for engineers that utilize closed-form analytical approaches for modeling levee underseepage. Further, they can be easily coded into a spreadsheet or other type of computer program for dayto-day analysis purposes. The associated guidance for the use of closed-form analytical models for performing levee underseepage is also useful for assessing the impact of boundary condition assumptions and analytical model selection (e.g., semipervious versus impervious blanket models) within the "blanket theory" modeling framework.

\section{Acknowledgements}

This material is based upon work supported by the University of Delaware Research Foundation (UDRF) under Award No. 08001107. The first author would like to acknowledge the support of the Fulbright Center in Finland and the 2012-2013 Fulbright-Tampere University of Technology Scholar Award, which provided support for work on this manuscript. The second author gratefully acknowledges the Royal Thai Government for providing financial support for his graduate education. The authors would like to acknowledge the suggestions and assistance of Prof. Victor Kaliakin of the University of Delaware.

\section{Notation}

The following symbols are used in this paper:

$h=$ total head in an aquifer;

$h_{1}=$ total head in the layer above confining layer 1 ;

$h_{2}=$ total head in the layer below confining layer 2 ;

$k_{1}=$ coefficient of permeability of semipermeable layer 1 ;

$k_{2}=$ coefficient of permeability of semipermeable layer 2;

$z_{1}=$ thickness of semipermeable layer 1 ;

$z_{2}=$ thickness of semipermeable layer 2 ;

$d=$ thickness of an aquifer or foundation layer (the pervious substratum);

$m_{1}=$ the hydraulic resistance of semipermeable confining layer 1 ;

$m_{2}=$ the hydraulic resistance of semipermeable confining layer 2 ;

$N=$ leakage

$\lambda=$ leakage factor;

$H=$ net head on levee;

$L_{1}=$ length of riverside blanket layer; 
$L_{2}=$ base width of levee;

$L_{3}=$ length of landside blanket layer;

$x_{1}=$ distance from effective seepage entry to riverside levee toe;

$x_{3}=$ distance from landside levee toe to effective seepage exit;

$k_{b}=$ vertical coefficient of permeability of the semipervious blanket;

$z_{b}=$ thickness of the semipervious blanket or top stratum;

$M=$ slope of the hydraulic gradient line;

$k_{f}=$ horizontal coefficient of permeability of the foundation (the pervious substratum);

$h_{t o e}=$ pressure head beneath the blanket layer at the landside levee toe;

$x_{t o e}=$ distance of interest beyond the landside levee toe;

$Q=$ quantity of seepage passing through the levee foundation per unit time;

$Q_{x y}=$ the net outward flux in a semiconfined element due to the flow in the $x$ - and $y$-directions;

$Q_{z 1}=$ the amount of water percolating out of a semiconfined element through the upper confining layer (layer 1) per unit time;

$Q_{z 2}=$ the amount of water percolating out of a semiconfined element through the lower confining layer (layer 2) per unit time;

$h_{A}=$ total head at the end of the riverside blanket;

$h_{B}=$ total head at the riverside levee toe;

$h_{C}=$ total head at the landside levee toe;

$h_{D}=$ total head at the end of the landside blanket.

\section{References}

Benjasupattananan, S., 2012. Deterministic and Probabilistic Approaches for Modeling Levee Underseepage. A Dissertation Submitted to the Faculty of the University of Delaware in Partial Fulfillment of the Requirements for the Degree of Doctor of Philosophy in Civil Engineering.

Bennett, P. T., 1946. The effect of blankets on seepage through pervious foundations. Trans. Am.Soc. Civ. Eng. 11, 215252.

Cedergren, H. R., 1989. Seepage, Drainage, and Flow Nets. John Wiley.

Darcy, H., 1856. Les Fontaines Publiques de la Ville de Dijon. Dalmont, Paris (in French).

Freeze, R. A., Cherry, J. A., 1979. Groundwater. Prentice Hall Inc., Englewood Cliffs, New Jersey.

Gabr, M. A., Taylor, H. M. Jr., Brizendine, A. L., Wolff, T. F., 1995. LEVEEMSU: Analysis Software for Levee Underseepage and Rehabilitation. Technical Report GL-95-9, US
Army Engineer Waterways Experiment Station, Vicksburg, MS.

Gabr, M.A., Wolff, T.F., Brizendine, A.L., Taylor, H. M., 1996. Underseepage analysis of levees on two-layer and three-layer foundation. Comput. Geotech. 18 (2), 85-107.

Harr, M. E., 1962. Groundwater and Seepage. McGraw-Hill, New York.

Hooghoudt, S. B., 1940. Algemene beschouwing van het probleem van de detailontwatering en de infiltratie door middel van parallel loopende drains, greppels, slooten en kanalen. No. 7 in de serie: Bijdragen tot de kennis van eenige natuurkundige grootheden van den grond. Bodemkundig Instituut te Groningen. Rijksuitgeverij Dienst van de Nderlandse Staatscourant. 's-Gravenhage, Algemeene Landsdrukkerij (in Dutch).

Peter, P., 1982. Canal and river levees. Developments of Civil Engineering, vol. 29. Elsevier/North-Holland, Inc., New York.

Strack, 1989. Groundwater Mechanics. Prentice-Hall, Inc.

Theis, C.V., 1935. The relation between the lowering of the piezometric surface and the rate and duration of discharge of a well using ground-water storage. Trans. Am. Geophys. Union 16, 519-524.

Thiem, G., 1906. Hydrologische methoden. J. M. Gebhardt, Leipzig, pp. 56 (in German).

Turnbull, W. J., Mansur, C.I., 1959. Investigation of underseepage - Mississippi river levees. J. Soil Mech. Found Div. ASCE 4, 41-93.

Turnbull, W. J., Mansur, C.I., 1961. Investigation of underseepage - Mississippi river levees. Trans. ASCE 126, 14861539.

Uginchus, A.A., 1935. Seepage through earth dams with aprons. Moskvavolgostroi 11, 67-79 (in Russian).

USACE, 1956a. US Army Corps of Engineers Waterways Experiment Station, Investigation of Underseepage and Its Control, Lower Mississippi River Levees. Technical Memorandum 3-424, Vicksburg, MS.

USACE, 1956b. US Army Corps of Engineers Waterways Experiment Station, Investigation of Underseepage and Its Control, Mississippi River Levees, St. Louis District, Alton to Gale, IL. Technical Memorandum 3-430, Vicksburg, MS.

USACE, 1993. Seepage Analysis and Control for Dams, Engineering Manual 1110-2-1901, US Army Corps of Engineers, April 1993, 392p.

USACE, 2000. Design and Construction of Levees, Engineering Manual 1110-2-1913, US Army Corps of Engineers, April 2000, 164p.

Verruijt, A., 1970. Theory of Groundwater Flow. Macmillan, London, 190p.

Wolff, T.F., 1989. Levee Underseepage Analysis for Special Foundation Conditions. Research Report REME-GT-11, US Army Corps of Engineers Waterways Experiment Station, Vicksburg, MS. 